\title{
A swarming-defective mutant of Proteus mirabilis lacking a putative cation-transporting membrane P-type ATPase
}

\author{
Hsin-Chih Lai,† Daniel Gygi, Gillian M. Fraser and Colin Hughes
}

\author{
Author for correspondence: Colin Hughes. Tel: +44 1223 333732. Fax: +44 1223333732. \\ e-mail: ch@mole.bio.cam.ac.uk
}

Department of Pathology, University of Cambridge, Tennis Court Road, Cambridge CB2 1QP, UK

\begin{abstract}
The motile TnphoA mutant IC24 of Proteus mirabilis U6450 generates an aberrant swarming colony, and was shown to be impaired in swarm cell differentiation, i.e. cell elongation and hyperflagellation, causing delayed and slower population migration across a solid growth medium. Levels of transcript from the flagellin filament gene flic, the flagellar master operon fIhDC, and the leucine-responsive regulatory protein gene Irp, a regulator of swarming differentiation, were reduced in IC24 mutant swarm cells. The transposon had inserted into a gene encoding a putative P-type ATPase closely related to those transporting cations across bacterial membranes. This ppa gene (Proteus P-type ATPase) was maximally expressed in differentiated swarm cells. The data suggest an effect of ion homeostasis on swarm cell differentiation, possibly mediated via the Irp-fihDC pathway.
\end{abstract}

Keywords: P-type ATPase, Proteus mirabilis, swarming

\section{INTRODUCTION}

Proteus mirabilis differentiates and undergoes multicellular swarming migration. When inoculated onto rich solid media, the typical short vegetative motile rods with few peritrichous flagella differentiate into swarm cells, multinucleate, aseptate filaments of up to 40 -fold vegetative cell length with $>50$-fold greater density of surface flagella. These form multicellular rafts which migrate rapidly away from the colony via cycles of differentiation and consolidation (pauses) (Allison \& Hughes, 1991a). Swarming is a factor in urinary tract pathogenicity of Proteus (Allison et al., 1994), and hyperexpression of flagellar genes in swarm cells is accompanied by the up-regulation of virulence genes, e.g. hpmA encoding haemolysin (Allison et al., 1992; Gygi et al., 1995a, 1997). Proteus transposon mutants with defects in swarming have indicated the involvement of a substantial number of genes in differentiation and subsequent population migration (Allison \& Hughes, 1991b; Belas et al., 1991). Hyperflagellation and a

tPresent address: School and Graduate Institute of Medical Technology, College of Medicine, National Taiwan University, Taipei, Taiwan, Republic of China.

The EMBL accession number for the sequence reported in this paper is AJ001437. capsular polysaccharide contribute to surface translocation (Gygi et al., 1995a, b, 1997; Belas, 1994), and cell elongation and the up-regulation of flagellar gene expression are closely coupled (Gygi et al., 1995a) via flbDC master operon expression (Furness et al., 1997; Hay et al., 1997). The stimuli that induce swarming are not clear, although surface contact, cell density, amino acids and other products have been discussed (Allison $\&$ Hughes, 1991a; Allison et al., 1993; Eberl et al., 1996; Gaisser \& Hughes, 1997). This report characterizes a transposon mutant, IC24, which was isolated due to its altered pattern of swarming, producing less pronounced or infrequent consolidation terraces (Allison \& Hughes, 1991a). Examination of the IC24 mutant revealed that swarm cell differentiation is dampened at both the phenotypic and transcriptional level and that it consequently migrates less vigorously than wild-type. The IC24 mutation is in a gene encoding a putative membrane cation-transporting P-type ATPase.

\section{METHODS}

Cell differentiation and motility assays. Swarming migration was monitored (Gygi et al., 1995b) on LB agar (1.5\%, w/v, agar), and swimming motility was monitored in soft LB agar $(0.3 \%, \mathrm{w} / \mathrm{v}$, agar $)$. Differentiation was assayed by seeding $200 \mu$ stationary phase vegetative cells $\left(\mathrm{OD}_{600} 4 \cdot 0\right)$ onto $\mathrm{LB}$ $1.5 \%(\mathrm{w} / \mathrm{v})$ agar and harvesting all bacteria from parallel agar 
plates at intervals (Gygi et al., 1995a). Cell surface flagellin from $\mathrm{OD}_{600} 5.0$ cells isolated from seeding differentiation plates was assayed by SDS-PAGE (12.5\% gel) and Coomassie brilliant blue staining of TCA-precipitated supernatant following vortexing of cells and centrifugation. The identity of flagellin was verified by Western blotting using anti- $P$. mirabilis flagellin antiserum (a gift from H. L. T. Mobley, University of Maryland, USA ; used at a dilution of $1: 10000)$. Cell elongation was assessed after $4 \mathrm{~h}$ seeding differentiation by harvesting cells $\left(O D_{600} 1.0\right)$ in formalin and photographing $>50$ cells under phase-contrast microscopy.

Cloning, sequencing and complementation. The mutated locus was isolated in plasmid pDG200 by digesting IC24 chromosomal DNA with EcoRI/HindIII, ligation of an approximately $2.3 \mathrm{kbp}$ fraction (previously determined by Southern blot hybridization) into pBluescript II KS (Stratagene) and selecting Escherichia coli XL-1 Blue transformants by hybridization with a probe internal to TnphoA (Gygi et al., 1995a). A phage library in 2 DashII (Gygi et al., $1995 \mathrm{a})$ was screened for the wild-type locus using a $1.6 \mathrm{kbp}$ $\mathrm{Xbal} /$ HindIII hybridization probe. Several overlapping phage were restriction-mapped. A $6.5 \mathrm{kbp}$ EcoRI fragment from phage $\lambda$ DII 24, was subcloned into pBluescript II KS. The resulting recombinant plasmid pHL1 was digested with Pst and religated to obtain plasmid pHL2, carrying $4.6 \mathrm{kbp}$ DNA. Plasmid pHL2 was digested with Ncol/EcoRV, followed by blunt-ending using T4 DNA polymerase and religation to obtain plasmid pDG201, carrying $2.4 \mathrm{kbp}$ insert DNA, which complemented the IC24 mutant swarming defect when supplied in trans. DNA manipulations, transformation and selection of $P$. mirabilis were carried out as described previously (Sambrook et al., 1989; Gygi et al., 1997). Both strands of plasmid DNA were sequenced by primer walking using a T7 kit (Pharmacia Biotech). The nucleotide sequence was analysed using GCG software (Devereux et al., 1984) and submitted to EMBL (accession no. AJ001437).

Messenger RNA (Northern) hybridization and transcript quantification. RNA was extracted by the hot-phenol method (Melton et al., 1984). Formamide/formaldehyde-denatured RNA (10 $\mu \mathrm{g}$ per track) was separated by electrophoresis through $1.2 \%$ agarose formaldehyde gels, transferred onto nitrocellulose filters (Hybond-C; Amersham) and hybridized as described by Gygi et al. (1995a). Equal loading of tracks was confirmed by staining rRNA bands on nitrocellulose filters with methylene blue (Sambrook et al., 1989). An approximately 820 bp Xbal-Spel fragment from pDG201 was used as a ppaA probe, an approximately $650 \mathrm{bp}$ HinclI fragment from plasmid $\mathrm{p} f i^{\prime} D \mathrm{DC}_{1} \mathrm{C}_{2}$ was used as a fliC probe (Belas $\&$ Flaherty, 1994), an approximately 800 bp Aval fragment from pRBF1 was the $A h D C$ probe (Furness et al., 1997) and an approximately 400 bp BglII-BssHII fragment from p200XP4 was the lrp probe (Hay et al., 1997). All were labelled by random priming with $\left[\alpha^{-32} \mathrm{P}\right] \mathrm{dATP}$ (Amersham). Autoradiographs were exposed to Fuji-RX film and transcript intensities were assessed using a Kodak Digital Science DC40 camera and Digital Science 1D software. Experimental error between individual determinations was approximately $10 \%$.

\section{RESULTS AND DISCUSSION}

\section{A mutant with a defect in swarming migration and swarm cell differentiation}

The TnphoA mutant IC24 of $P$. mirabilis U6450 was previously identified due to its aberrant swarming colony on LB medium containing $1.5 \%(\mathrm{w} / \mathrm{v})$ agar, (a)

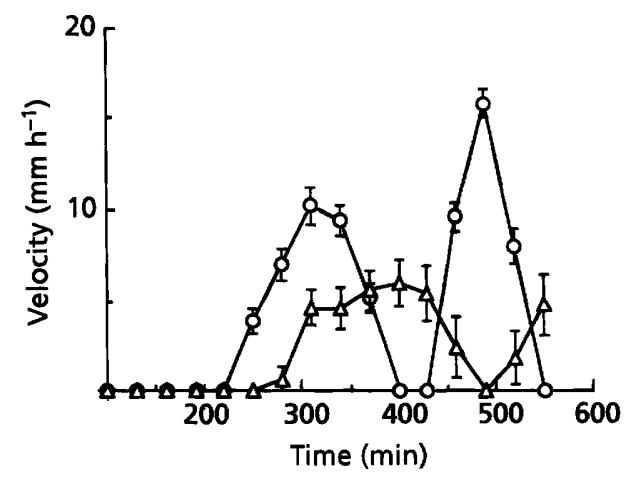

(b)
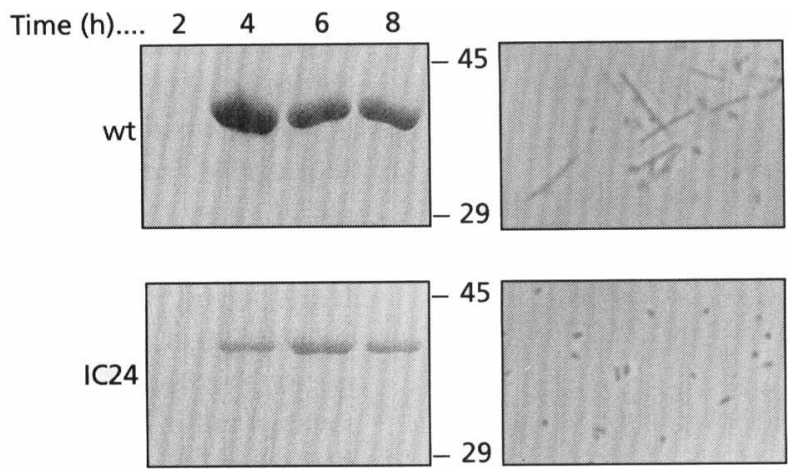

Fig. 1. Phenotype of the IC24 mutant. (a) Translocation velocities of wild-type $(O)$ and IC24 mutant $(\triangle)$ swarm fronts. Error bars indicate mean SD from determinations on duplicate plates. (b) Left-hand side, surface flagellin of wild-type (wt) and mutant (IC24) during seeding differentiation at 2, 4, 6 and $8 \mathrm{~h}$ after inoculation, Coomassie-blue-stained after SDS-PAGE (12.5\% gel). Protein marker sizes are in $\mathrm{kDa}$. Right-hand side, cells of wild-type and IC24 mutant at $4 \mathrm{~h}$ differentiation under phase-contrast microscopy.

forming less pronounced ('infrequent') consolidation terraces than wild-type (Allison et al., 1991b). Inoculation of this mutant into semi-solid LB medium $(0.3 \%$, $\mathrm{w} / \mathrm{v}$, agar) revealed no reduction in the swimming motility of individual cells compared to wild-type, nor was there a change in growth rate in LB broth or on LB agar, both mutant and wild-type having midexponential generation times of $31 \mathrm{~min}( \pm 1 \cdot 2 \mathrm{~min})$. Migration of the swarm edges of both wild-type and IC24 cell populations was monitored on LB $1.5 \%(\mathrm{w} / \mathrm{v})$ agar plates (Fig. 1a), revealing that the mutant was slower to initiate migration and that it achieved at most two-thirds maximum velocity. It migrated for longer than wild-type (the time until the first consolidation pause of the IC24 mutant was approximately $90 \mathrm{~min}$ later).

Wild-type and IC24 mutant cell differentiation was assessed by high cell density seeding of stationary phase broth cultures onto LB $1.5 \%(w / v)$ agar, which induces vegetative cells to undergo a cycle of differentiation (Gygi et al., 1995a, b). Surface flagellin expression by the IC24 mutant was still induced but was significantly 


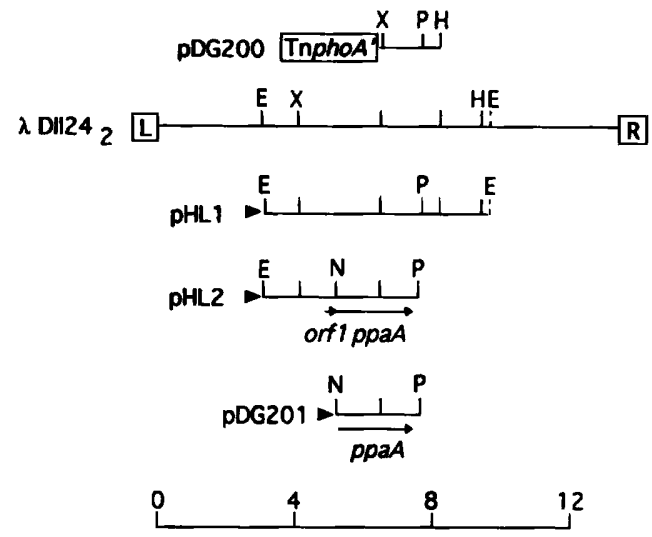

Fig. 2. Isolation and characterization of the IC24 genetic locus. The recombinant plasmid pDG200 is pBluescript II KS containing an approximately $2.3 \mathrm{kbp}$ EcoRl-HindIII fragment from mutant IC24 (TnphoA portion not drawn to scale), identified as described by Gygi et al. (1995a, b). Isolation of the intact locus was achieved by hybridization of a $\lambda$ Dashll library of $P$. mirabilis wild-type (Gygi et al., 1995a) with a $1.6 \mathrm{kbp}$ Xbal-HindIII probe from pDG200. Plasmid pHL1 is pBluescript II KS containing an approximately $6.5 \mathrm{kbp}$ EcoRI insert. Plasmid pHL2 is pBluescript II KS carrying an approximately $4.6 \mathrm{kbp}$ EcoRI-Pstl insert. Plasmid pDG201 is pBluescript II KS containing an approximately $2.4 \mathrm{kbp} \mathrm{Ncol-Pstl}$ insert. The orientation of the pBluescript II KS lac promoter is indicated by an arrow. The scale indicates kbp. E, EcoRl; H, HindIII; N, Ncol; P, Pstl; X, Xbal.

reduced compared to wild-type (Fig. 1b), being between four- and eightfold less in differentiating cells at the $4 \mathrm{~h}$ point as determined by comparison of twofold serial dilutions of isolated flagellin (not shown). Western blotting of total cellular flagellin with anti-FliC (flagellin) antibody showed a comparable reduction and did not indicate intracellular accumulation of flagellin by the mutant (not shown). Differentiation-specific cell elongation was also reduced in the IC24 mutant (Fig. 1b) by on average threefold at $4 \mathrm{~h}$, and unlike wild-type the mutant failed to generate a significant population of highly elongated cells (Fig. 1b).

\section{A lesion in a gene encoding a P-type putative cation- translocating membrane ATPase}

Initial sequencing of the DNA flanking the transposon cloned in pDG200 (Fig. 2) revealed an insertion in an ORF closely related to bacterial P-type ATPases. The smallest recombinant plasmid carrying DNA of the wild-type locus that was able to restore in trans wildtype swarming by the IC24 mutant was pDG201, in which a $2.4 \mathrm{kbp}$ fragment contained a $2076 \mathrm{bp}$ ORF, disrupted in the mutant, transcribed by the vector lac promoter (Fig. 2). Further sequencing of pDG201 and plasmid pHL2 revealed that $16 \mathrm{bp} 5^{\prime}$ of this ORF was a 297 bp ORF, orf1, which was N-terminally truncated on pDG201. Both ORFs were preceded by putative ribosome-binding sites but no potential promoter consensus sequences were obvious. A potential transcription terminator sequence $19 \mathrm{bp} 3^{\prime}$ of the $2076 \mathrm{bp}$ ORF was identified using the TERMINATOR program (Devereux $e t$ al., 1984).

The disrupted ORF, which we call ppaA ( roteus $\underline{P}$-type ATPase), encodes a predicted $73.95 \mathrm{kDa}$ polypeptide which is related to bacterial P-type cation-transporting membrane ATPases. The PpaA sequence is $58 \%$ identical to that of the zinc-transporting ATPase ZntA of $E$. coli (Sofia et al., 1994; Beard et al., 1997; Rensing et al., 1997), $35 \%$ identical to CadA (Nucifora et al., 1989) or CadD of Staphylococcus aureus (SWISS-PROT accession no. P37386) and $34 \%$ identical to the potassium/copper-transporting ATPase CopA of Enterococcus hirae (Odermatt et al., 1993). PpaA shares protein motifs with other putative bacterial P-type cation-transporting ATPases (Silver \& Walderhaug, 1992 ), notably the N-terminal heavy metal binding site 3-Cys-X-X-Cys-6. Other features are shared with the Ptype ATPase family such as the conserved tetrapeptide 233-Thr-Gly-Glu-Ser-236 found in the phosphatase domain and the phosphorylation site constituted by the 7-amino-acid motif 381-Asp-Lys-Thr-Gly-Thr-LeuThr-387. PpaA is hydrophobic, which would be consistent with it being a membrane protein (Fig. 3). The putative ion translocation region of $\mathrm{PpaA}$, spanning residues 335-367, contains proline (amino acid 338) located within a hydrophobic domain. While this proline is conserved in all P-type ATPases, it appears to be flanked by cysteines in metal-ion-translocating enzymes like the copper transporters CopA or CopB of Ent. hirae (Odermatt et al., 1993; Silver \& Walderhaug, 1992). A possible function of $\mathrm{PpaA}$ in cation transport was investigated by comparing the growth rates of wild-type and mutant in the presence of monovalent and bivalent cations in minimal medium, but no difference was observed, the mid-exponential generation times being $51 \mathrm{~min}( \pm 2 \mathrm{~min}$ ) for both strains under all conditions tested (not shown). However, this does not exclude a role for PpaA in cation transport as experimental conditions might not have been optimal and there may be other transporters in $P$. mirabilis with less specific specificity. This is supported by the finding that plasmid pHL1 (Fig. 2) can complement the cation-transport defect of an E. coli zntA null mutant (C. Rensing \& B. Rosen, personal communication). Furthermore, the 99 amino-acid (11.1 kDa) Orf1, which does not show significant primary sequence identity to any database entry, is unusually rich in histidines $(21 \%)$, contains three cysteine pairs, and is predicted to be highly hydrophilic and negatively charged (Fig. 3). These features are reminiscent of the 60-amino-acid Hpn polypeptide of Helicobacter pylori, which possesses a high histidine content $(47 \%)$, two cysteine pairs, and which binds, in descending order of affinity, the cations $\mathrm{Ni}^{2+}, \mathrm{Zn}^{2+}, \mathrm{Co}^{2+}, \mathrm{Cu}^{2+}, \mathrm{Cd}^{2+}$ and $\mathrm{Mn}^{2+}$ (Gilbert et al., 1995).

\section{ppaA expression is maximal in swarm cells}

Northern blot hybridization of wild-type $P$. mirabilis RNA collected during a swarming differentiation cycle (Gygi et al., 1997) revealed that expression of the ppaA 

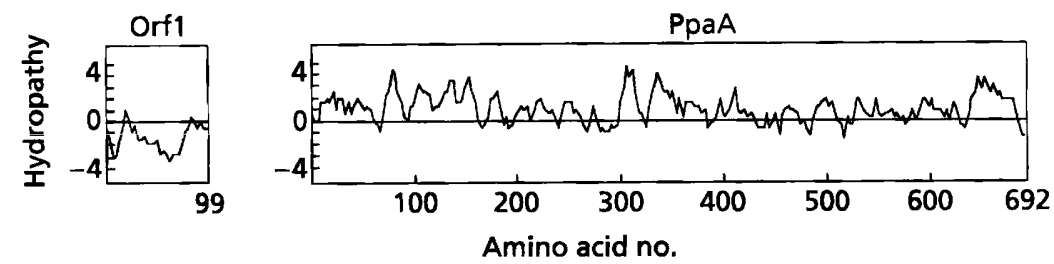

Fig. 3. Hydrophobicity profiles of Orf1 and PpaA with amino acid scale (Kyte \& Doolittle, 1982).
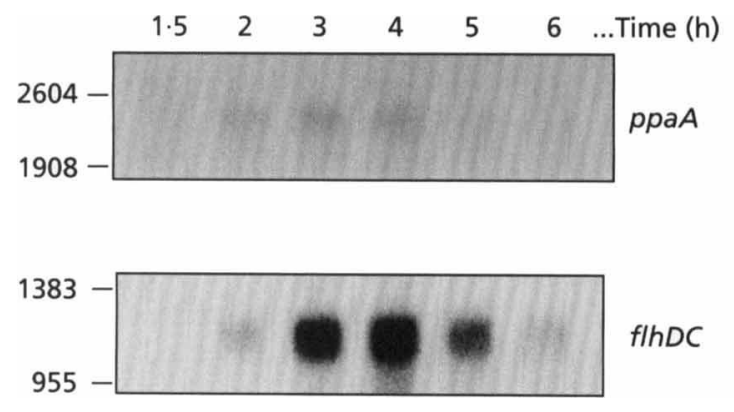

Fig. 4. Wild-type ppaA and flhDC mRNA during differentiation into swarm cells. RNA was extracted 1.5-6 h after seeding onto LB agar. Northern blots were exposed at $-80^{\circ} \mathrm{C}$ with intensifying screens for 72 and $6 h$, respectively, to visualize the ppaA and fihDC transcripts. Transcript sizes (kbp) were estimated by comparison to in vitro transcript RNA markers (Promega).

gene was maximal in differentiated swarm cells (Fig. 4). This pattern is similar to the expression of the strongly induced $f h D C$ flagellar master operon (Fig. 4; Furness et al., 1997), but the $p p a A$ mRNA was present at an approximately 100 -fold lower concentration. The approximately $2.5 \mathrm{kbp} p p a A$ transcript size of the $p p a A$ mRNA is compatible with transcription initiating $5^{\prime}$ of orf 1 and terminating at the predicted terminator sequence $3^{\prime}$ of $p p a A$.

\section{Reduced expression of the fIhDC master operon and Irp regulator in the ppaA mutant}

The reduction in cell elongation and surface flagella during differentiation of the mutant suggested a defect in the expression of the flagellar master operon $f h D C$, the levels of which control flagellar biogenesis and cell division, and correlate with swarm-specific cell hyperflagellation and filamentation in Serratia liquefaciens and P. mirabilis (Eberl et al., 1996; Furness et al., 1997). This was investigated by Northern blot hybridization of RNA samples collected at regular intervals during a seeding differentiation cycle (Gygi et al., 1997). The $1.3 \mathrm{kbp}$ flagellin $f i \mathrm{C}$ transcript was reduced throughout this assay by approximately twofold in the mutant (Fig. 5 ), less pronounced than the reduction in surface and total cellular flagellin, as were levels of the approximately $1.1 \mathrm{kbp}$ fihDC transcript (Furness et al., 1997) and the approximately $700 \mathrm{bp}$ mRNA of the $\operatorname{lrp}$ gene (Fig. 5), expression of which is a requirement for Proteus swarming, specifically flagellar gene hierarchy expression and cell elongation (probably via $f l b D C$ ) (Hay et al., 1997).

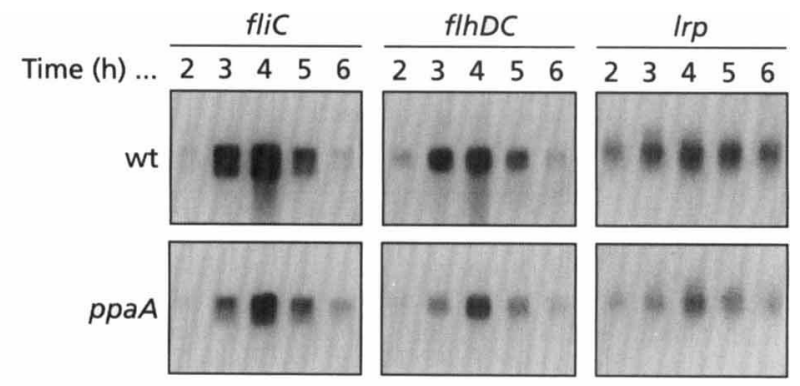

Fig. 5. mRNA levels in wild-type (wt) and ppaA mutant during seeding differentiation. RNA was extracted 2-6 $\mathrm{h}$ after seeding. Northern blots were exposed for $2 \mathrm{~h}$ at room temperature without intensifying screens for flic transcript, and for $6 \mathrm{~h}$ and $18 \mathrm{~h}$ at $-80^{\circ} \mathrm{C}$ with intensifying screens for the flhDC and Irp transcripts, respectively.

In summary, the results show that the IC24 mutant has lost a P-type ATPase, most probably a membrane cation transporter, that reduces swarming differentiation and dampens down the initiation and velocity of swarming. A reduction in differentiation to the hyperflagellated elongated form appears to be due to a decrease in transcription of flagellar genes, in particular reduced expression of the flagellar master operon $f h D C$. The observation that the $p p a A$ mutant has correspondingly reduced expression of $\operatorname{lr} p$, which is essential for swarmspecific hyperexpression of flhDC (Hay et al., 1997), suggests that cations might influence expression of flagella via $l r p$. An effect of ion homeostasis on swarming would not be surprising as $\mathrm{NaCl}$ prevents swarming (Allison \& Hughes, 1991a) and represses E. coli flagellar biogenesis at the transcriptional level (Shi et al., 1993), and intracellular $\mathrm{Ca}^{2+}$ levels influence the chemotactic response in E. coli (Tisa \& Adler, 1992). Our findings appear to lend weight to the idea that ion concentration is one of a number of factors influencing bacterial swarming differentiation.

\section{ACKNOWLEDGEMENTS}

We thank C. Rensing and B. Rosen, Wayne State University School of Medicine, Detroit, USA, for communicating results. This work was financed by the Wellcome Trust.

\section{REFERENCES}

Allison, C. \& Hughes, C. (1991a). Bacterial swarming: an example of prokaryotic differentiation and multicellular behaviour. Sci Prog 75, 403-422.

Allison, C. \& Hughes, C. (1991b). Closely linked genetic loci 
required for swarm cell differentiation and multicellular migration by Proteus mirabilis. Mol Microbiol 5, 1975-1982.

Allison, C., Lai, H.-C. \& Hughes, C. (1992). Co-ordinate expression of virulence genes during swarm-cell differentiation and population migration of Proteus mirabilis. Mol Microbiol 6, $1583-1591$.

Allison, C., Lai, H.-C., Gygi, D. \& Hughes, C. (1993). Cell differentiation of Proteus mirabilis is initiated by glutamine, a specific chemoattractant for swarming cells. Mol Microbiol 8, $53-60$.

Allison, C., Emody, L., Coleman, N. \& Hughes, C. (1994). The role of swarm cell differentiation and multicellular migration in the uropathogenicity of Proteus mirabilis. J Infect Dis 169, 1155-1158.

Beard, S. J., Hashim, R., Membrillo-Hernandez, J., Hughes, M. N. \& Poole, R. K. (1997). Zinc (II) tolerance in Escherichia coli K12: evidence that the $z n t A$ gene (o732) encodes a cation transport ATPase. Mol Microbiol 25, 883-891.

Belas, R. (1994). Expression of multiple flagellin-encoding genes from Proteus mirabilis. J Bacteriol 176, 7169-7181.

Belas, R. \& Flaherty, D. (1994). Sequence and genetic analysis of multiple flagellin-encoding genes from Proteus mirabilis. Gene 128, 33-41.

Belas, R., Erskine, D. \& Flaherty, D. (1991). Proteus mirabilis mutants defective in swarmer cell differentiation and multicellular behaviour. J Bacteriol 173, 6279-6288.

Devereux, J., Haeberli, P. \& Smithies, O. (1984). A comprehensive set of sequence analysis programs for the VAX. Nucleic Acids Res 12, 387-395.

Eberl, L., Christiansen, G., Molin, S. \& Givskov, M. L. (1996). Differentiation of Serratia liquefaciens into swarm cells is controlled by the expression of the $f h D$ master operon. J Bacteriol 178, 554-559.

Furness, R. B., Fraser, G. M., Hay, N. A. \& Hughes, C. (1997). Negative feedback from a Proteus Class II flagellum export defect to the $A h D C$ master operon controlling cell division and flagellum assembly. J Bacteriol 179, 5585-5588.

Gaisser, S. \& Hughes, C. (1997). A locus coding for putative nonribosomal peptide/polyketide synthase functions is mutated in a swarming-defective Proteus mirabilis strain. Mol Gen Genet 253, 415-427.

Gilbert, J. V., Ramakrishna, J., Sunderman, F. W., Jr, Wright, A. \& Plaut, A. G. (1995). Protein Hpn : cloning and characterization of a histidine-rich metal-binding polypeptide in Helicobacter pylori and Helicobacter mustelae. Infect Immun 63, 2682-2688.

Gygi, D., Bailey, M. J., Allison, C. \& Hughes, C. (1995a). Requirement for FlhA in flagella assembly and swarm cell differentiation by Proteus mirabilis. Mol Microbiol 15, 761-769.
Gygi, D., Rahman, M. M., Lai, H.-C., Carison, R., Guard-Petter, J. \& Hughes, C. (1995b). A cell-surface polysaccharide that facilitates rapid population migration by differentiated swarm cells of Proteus mirabilis. Mol Microbiol 17, 1167-1175.

Gygi, D., Fraser, G., Dufour, A. \& Hughes, C. (1997). A motile but non-swarming mutant of Proteus mirabilis lacks FlgN, a facilitator of flagella filament assembly. Mol Microbiol 25, 597-604.

Hay, N. A., Tipper, J. T., Gygi, D. \& Hughes, C. (1997). A nonswarming mutant of Proteus mirabilis lacks the Lrp global transcriptional regulator. $J$ Bacteriol 179, 4741-4746.

Kyte, J. \& Doolittle, R. F. (1982). A simple method for displaying the hydropathic character of a protein. J Mol Biol 157, 105-132.

Melton, D. A., Krieg, P. A., Rebagliati, M. R., Maniatis, T., Zinn, K. \& Green, M. R. (1984). Efficient in vitro synthesis of biologically active RNA and RNA hybridization probes from plasmids containing a bacteriophage SP6 promoter. Nucleic Acids Res 12, 7035-7056.

Nucifora, G., Chu, L., Misra, T. K. \& Silver, S. (1989). Cadmium resistance from Staphylococcus aureus plasmid pI258 CadA gene results from a cadmium-efflux ATPase. Proc Natl Acad Sci USA 86, 3544-3548.

Odermatt, A., Suter, H., Krapf, R. \& Solioz, M. (1993). Primary structure of 2 P-type ATPases involved in copper homeostasis in Enterococcus birae. J Biol Chem 268, 12775-12779.

Rensing, C., Bhartati, M. \& Rosen, B. P. (1997). The $z n t A$ gene of Escherichia coli encodes a $\mathrm{Zn}$ (II)-translocating P-type ATPase. Proc Natl Acad Sci USA 94, 14326-14331.

Sambrook, J., Fritsch, E. F. \& Maniatis, T. (1989). Molecular Cloning: a Laboratory Manual, 2nd edn. Cold Spring Harbor, NY: Cold Spring Harbor Laboratory.

Shi, N. Y., Li, C. Y., Louise, C. J. \& Adler, J. (1993). Mechanism of adverse conditions causing lack of flagella in Escherichia coli. $J$ Bacteriol 175, 2236-2240.

Silver, S. \& Walderhaug, G. (1992). Gene regulation of plasmidand chromosome-determined inorganic ion transport in bacteria. Microbiol Rev 56, 195-228.

Sofia, H. J., Burland, V., Daniels, D. L., Plunkett, G., III \& Blattner, F. R. (1994). Analysis of the Escherichia coli. DNA sequence of the region from 76.0-minutes to 81.5 minutes. Nucleic Acids Res 22, 2576-2586.

Tisa, L. S. \& Adler, J. (1992). Calcium ions are involved in Escherichia coli chemotaxis. Proc Natl Acad Sci USA 89, 11804-11808.

Received 10 September 1997; revised 23 February 1998; accepted 26 March 1998. 